\title{
AS CIÊNCIAS SOCIAIS E A \\ DIVERSIDADE DOS SOTAQUES
}

\section{Renato Ortiz}

Existe atualmente um mal-estar do universalismo. A revolução digital, os meios de comunicação, as finanças, as viagens, o imaginário coletivo do consumo, nos levam a sublinhar os traços compartilhados desses tempos de globalização. A própria noção de espaço se transformou, os símbolos e signos culturais adquirem uma feição desterritorializa$\mathrm{da}$, descolados de suas cores nacionais ou regionais, redefinindo-se no âmbito da modernidade-mundo. Entretanto, diante desse movimento real das sociedades uma desconfiança se insinua. O mal-estar é uma sensação imperceptível de desconforto. Ele é palpável mas disperso, sua manifestação é sinuosa, difícil de ser identificada. Porém, malgrado sua imprecisão, ele é evidente, tangível. A situação de globalização implica a necessidade de se buscar respostas consensuais relativas aos problemas comuns, mas nossas certezas em relação às crenças anteriores

Artigo recebido em 08/12/2010

Aprovado em 04/04/2011 se esvaneceram. O universalismo dos filósofos iluministas já não nos serve de guia.

Paradoxalmente, no momento em que determinada situação histórica aproxima a todos, o universal, como categoria política e filosófica, perde em densidade e convencimento. Ressurge, assim, um debate antigo, mas que agora se reveste de formas distintas: o relativismo. Este é um tema clássico nas ciências sociais devido à natureza do próprio saber sociológico. A existência de diversas correntes teóricas revelam as dificuldades para a constituição de um paradigma único, capaz de se impor para a disciplina como um todo. Há ainda outros elementos importantes: elas são históricas e a subjetividade de seus praticantes é uma dimensão decisiva no entendimento dos fenômenos sociais. Entretanto, apesar das controvérsias, os embates teóricos tendem a se concentrar num problema comum, qual seja, em que medida as explicações sociológicas ou antropológicas teriam ou não abrangência "uni- 
versal" (ver, entre outros, Ernest Gellner, 1985). A dúvida, como em qualquer outra atividade científica, seria o de delimitar a validade do pensamento, retirando-o dos traços restritivos de cada experiência. A discussão focaliza, portanto, temas de caráter teórico e metodológico. Mas a questão da diversidade das interpretaçôes pode ser abordada de outra forma, considerando-se não tanto os impasses do método, mas como as ciências sociais se constituem historicamente. Neste caso, somos obrigados a nos perguntar sobre o contexto no qual elas se realizam.

Penso que as mudanças ocorridas no âmbito da modernidade-mundo não se restringem às esferas econômica ou sociais, mas incidem no plano intelectual. A prática sociológica ajusta-se mal à imagem cultivada pelo seu legado clássico, ideal materializado em livros, textos e programas de formação profissional. Tampouco é possível pensá-la, como no passado recente, como algo exclusivamente restrito ao universo da epistemologia. As transformações ocorridas incidem tanto no nível dos conceitos como nas formas de sua organização. A diversidade das interpretações se acelera, acentuando o mal-estar contemporâneo.

Um primeiro aspecto deste panorama conturbado diz respeito à crítica ao eurocentrismo. Ela possui, como no passado, uma forte inclinação política e ideológica. Quando Hobson escreve Imperialism: a study, publicado em 1902, no qual o conceito de imperialismo surge pela primeira vez, uma das dimensões sublinhadas, ao lado da econômica, refere-se à dominação cultural (Hobson, 1968). As naçôes industrializadas, compostas de "raças superiores", teriam o dever moral de ensinar às "inferiores" a trilha da civilização. O imperialismo, fenômeno fundamentalmente econômico, se justificaria e se legitimaria mediante uma concepção de mundo parcial e distorcida. Franz Fanon (1961) também considerava o dualismo da situação colonial um momento de alienação cultural. O predomínio do homem branco, traduzido em termos hegelianos na oposição entre senhor e escravo, encontraria no reino da consciência sua forma mais elaborada de ocultamento. O Ser nacional, submetido às forças opressoras do colonialismo, era incapaz de afirmar sua autenticidade alienada. Daí sua luta pela independência dos países periféricos; somente ela propiciaria uma superação da dicotomia colonizador/ colonizado. Esta dimensão política encontra-se presente em diversos escritos atuais, nos quais o universalismo é visto como retórica de poder, técnica de dominação. Samir Amin (1988), o considera um culturalismo, isto é, uma falsa consciência específica da cultura do capitalismo - ele acredita na existência de um universalismo "verdadeiro", "não truncado", decorrente da superação do modo de produção capitalista. ${ }^{1}$ A problemática da dominação política e econômica é recorrente nos estudos sobre o imperialismo, na literatura pós-colonialista, assim como nos debates sobre o "direito de intervenção" dos Estados Unidos e da União Europeia em outros países (por exemplo, no combate ao terrorismo).

Existe, entretanto, outro aspecto que gostaria de sublinhar, cuja natureza é mais reflexiva, teórica (não quero dizer com isso que o político seja negligenciável). Antes, porém, chamo a atenção para a atualidade de muitos dos argumentos apresentados ao longo desse debate. Eles são recentes e distinguem-se da visão anterior na qual o etnocentrismo era objeto de consideraçôes críticas. Refiro-me particularmente à literatura antropológica. A recusa à arrogância ocidental, quando se depara com grupos indígenas, é recorrente entre os culturalistas norte-americanos; eles questionam a utilização de conceitos como "bárbaros", "selvagens", e são avessos ao darwinismo social. $\mathrm{O}$ mesmo pode ser dito a respeito de um livro como Race et histoire, de Lévi-Strauss: o elogio que se faz da diversidade das culturas contrasta com o etnocentrismo e sua fé inquebrantável no progresso da humanidade. $\mathrm{Na}$ verdade, a problemática da alteridade encontra-se no cerne do pensamento antropológico. Para se constituir como um saber específico, a antropologia se afasta da modernidade debruçando-se sobre os povos indígenas. A questão do Outro implica um descentramento do pesquisador em relação à sua própria cultura. Relativizar o olhar "ocidental” torna-se um imperativo categórico do trabalho etnológico. Porém, nesta fase em que a antropologia se consolida como disciplina acadêmica, o solo epistemológico no qual ela se sustenta, em momento algum, é questionado (isso fica claro na relação tensa e ambígua que ela entretém com a temática do colonialismo). ${ }^{2}$ Dito de outra forma, não se desconfia das premissas que o antecedem e o fundamentam. 
Este é justamente o traço essencial de toda uma literatura que emerge nos anos de 1980 e se desenvolve ao longo da década seguinte. Ela não se satisfaz em desnudar os traços arbitrários de determinada visão acadêmica; sua ambição é maior, revisar a herança intelectual do Iluminismo, cuja realização se faz em áreas distintas, história, sociologia, ciência política, antropologia. Tomo o exemplo de Edward Said - sua tese sobre o orientalismo é sugestiva (Said, [1978] 1989). Para ele tal conceito é uma representação, um discurso (nos termos em que Focault o define) que funda um campo de saber. Não se trata tanto de uma ideologia, mas de um conjunto a priori construído a partir de uma relação de força, o colonialismo europeu, que funda uma área de conhecimento. O que está em causa é a forma de se "fazer ciência", a maneira pela qual determinado discurso, erudito e sofisticado, se constitui como legítimo, malgrado sua fragilidade de ordem conceitual. A noção de Oriente determina de forma arbitrária uma área cultural cujas fronteiras geográficas coincidem com as fronteiras epistemológicas de uma disciplina, a rigor, inexistente. A crítica de Said esvazia o sentido de uma categoria cuja solidez se sustentava pela distorção das lentes de um olhar desfocado. Outro exemplo, o livro de Martin Bernal, Black Athena (1987). Erudito, sinólogo de formação, conhecedor do grego antigo, ele questiona um tipo de genealogia das ideias recorrente na história da filosofia: a razão emerge na Grécia Antiga e se realiza na Europa. Nesta perspectiva, haveria uma linha de continuidade ao longo da história. Seus estudos demonstram, no entanto, que a Antiguidade greco-romana é uma ilusão falaciosa. A tradição helênica encontra sua fonte de inspiração no mundo egípcio que a antecedia e a envolvia, fascínio que se exerce e se prolonga no seio do pensamento europeu. Somente no século XVIII tal fascinação (o autor a denomina de "modelo da antiguidade") é substituída pela hegemonia helênica. Por isso Bernal fala da "fabricação" de uma Grécia Antiga, de origem recente, que estabeleceria um relato linear entre as virtudes da razão filosófica e seus únicos fundadores, os gregos.

Esta retomada conceitual, os leitores de Derrida dizem des-construção, problematiza sobretudo a forma como se elaborou certa concepção do passado. A isso Jack Goody denomina "o roubo da história”: civilização, capitalismo, democracia, racionalidade, num passe de mágica, transformam-se em valores europeus e constituem a maneira ideal de se pensar e ordenar as sociedades e os povos (Goody, 2006; Blaut, 1993). Assim, as causas do progresso podem ser creditadas à "mente", ao "espírito" ocidental, no qual prevaleceria a criatividade, a imaginação, a invenção, a inovação, um sentido ético; a ausência desses valores teria condenado ao atraso o restante da humanidade. Há neste tipo de argumentação muito de opacidade e pouco de esclarecimento. A revolução industrial, na sua origem inglesa, expandindo-se posteriormente para toda a Europa, transforma-se subitamente na manifestação inequívoca da exceção ocidental (Hobsbawm nos relembra o óbvio: ela é inglesa); a racionalidade, fator determinante do dinamismo europeu, sobrepõe-se ao imobilismo, à irracionalidade ou ao despotismo asiático (Marx pensava existir um modo de produção específico dessas sociedades). Um exemplo interessante é a China. Hegel costumava dizer que ela repousava imóvel no "reino da duração", incapaz de se transformar a si mesmo; o mundo chinês, avesso às mudanças, conteria uma história sem história, a repetição incessante de uma "ruína majestosa". Esta concepção, um continente isolado e economicamente estagnado, impregna as interpretaçōes de diversos autores, nas quais o peso da tradição é um contraste recorrente ao espírito inovador ocidental. ${ }^{3}$ São inúmeros os estudos que sublinham a ineficiência de sua indústria naval, assim como o débil florescimento das trocas comerciais internacionais. Se no continente europeu um instrumento como a bússola impulsiona as grandes descobertas marítimas e a conquista da América, decisivas para o capitalismo, na China ela teria permanecido um objeto de mera curiosidade. No entanto, os estudos de Pomeranz (2000) demonstram que até 1800 não existia, entre o mundo europeu e o chinês, divergência radical em termos de desenvolvimento econômico; isso irá ocorrer somente após a Revolução Industrial. Na literatura recente surge, inclusive, uma hipótese ousada, as origens chinesas da industrialização inglesa (como toda hipótese, passível de discussão) (Hobson, 2004). Uma maneira alegórica de se caracterizar esta re- 
leitura da história encontra-se num dos capítulos de um belo livro de Fernández-Armesto, Milênio (1996). Com um titulo curioso, "O jardim zoológico dos Ming", ele conta como em 1415 o imperador da China, acompanhado de um longo séquito de cortesãos, foi receber em Pequim um ilustre recém-chegado. Vindo do outro extremo do oceano Índico, o visitante desconhecido foi descrito como sendo um animal com "um corpo de veado, cauda de boi, um chifre carnudo, sem osso, e manchas luminosas, como uma névoa vermelha ou arroxeada; um andar imponente e observa em todos os seus movimentos um ritmo compassado". Difícil de discernir pela descrição fornecida que se tratava de uma girafa; ela vinha enriquecer uma longa coleção de bichos do jardim zoológico imperial, o qual contava com inúmeras outras espécies (leōes, leopardos, avestruzes, dromedários, zebras, rinocerontes, antílopes). Procedentes das mais diversas origens - Bengala, Arábia, África Oriental -, eles testemunham a curiosidade e o interesse pelo mundo afora, o que demonstram as sofisticadas técnicas de navegação que os chineses desenvolveram. Na verdade, a dinastia Ming impulsionou as incursões marítimas iniciadas com a conquista dos mongóis no século XI; foi assim que os juncos chineses, carregados com artigos exóticos, chegaram ao Oriente Médio desembarcando na corte egípcia. $\mathrm{O}$ argumento do imobilismo e do isolacionismo encaixam-se mal neste quadro. A pergunta correta a fazer seria: por que não houve continuidade deste movimento expansionista? A resposta de Fernández-Armesto é interessante. Ele explica que durante a dinastia Ming havia no império celestial um equilíbrio entre interesses diversos e antagônicos; junto ao poder central atuavam os burocratas confucianistas, as chefias militares, a casta dos eunucos, os conselheiros estrangeiros, os cleros budista e taoísta, o lobby dos mercadores. A situação altera-se radicalmente quando o imperador Hung-hsi assume o trono em 1424. O grupo confucianista ampara-se do poder e, contrário aos valores materialistas dos comerciantes, irá abolir o impulso anterior. Não foi a ausência de uma racionalidade tipo ocidental que inibiu o desenvolvimento chinês, mas uma orientação política exercida pelo Estado numa conjuntura histórica específica.
Também na esfera sociológica, a crítica ao eurocentrismo manifesta-se. É difícil ler nos dias de hoje, a não ser com uma razoável dose de distanciamento, a famosa introdução de $A$ ética protestante e o espirito capitalista; nela Weber sintetiza as qualidades intrínsecas do mundo europeu, condiçãao espiritual que se manifestaria nos mais diferentes domínios: música, arquitetura, direito, economia. Assim, apenas no Ocidente existiria a ciência; à astronomia babilônica faltaria a fundamentação matemática, à geometria indiana, a prova racional, à historiografia chinesa, o método de Tucídides, às teorias políticas asiáticas, a sistematicidade de um Maquiavel. A ogiva tinha sido utilizada na Ásia como meio de decoração, contudo o uso racional da abóbada gótica seria fruto da Idade Média; da mesma maneira, a música racional, o contraponto, a harmonia, as tríades, as orquestras, as sonatas, as sinfonias, as óperas, só teriam sentido na Europa ocidental. O projeto weberiano pretendia compreender como emergiu uma racionalidade cujos fundamentos seriam excepcionais, expressão de uma singularidade civilizatória. O enorme esforço comparativo que ele realiza (Weber é um comparativista extraordinário e não possui uma perspectiva teleológica da história) tem um objetivo explícito: explicar por que em outras civilizaçôes, como na China e na Índia, o caminho da racionalização não se completou. $\mathrm{O}$ problema é que esse tipo de interpretação é por demais frágil. Os traços percebidos como únicos e excepcionais - racionalidade, contabilidade econômica, propensão ao comércio, ética religiosa - são partilhados por diversos outros povos. ${ }^{4} \mathrm{~A}$ mesma sensação de incongruência ressentimos diante de um livro clássico como o de Burckhardt, A civilização do Renascimento na Itália. Publicado em 1860, ele reflete uma consciência europeia em busca de suas raízes. Burckhardt acredita que a noção de indivíduo surge e desenvolve-se neste período de afluência, daí seu intuito em apreender geneticamente a constituição do Eu, legado ímpar de uma civilização. O Renascimento seria o momento da descoberta do homem, do seu interior, de sua individualidade. Por isso floresceriam na Itália renascentista as biografias e os retratos; o relato narrado na primeira pessoa, assim como as personalidades estampadas nas pinturas, além dos autorretratos de pintores como Vasari e 
Ticiano, revelariam o surgimento de uma dimensão interna à vida humana até então, sufocada pelas malhas da tradição. No entanto, basta lermos sobre o "nascimento do indivíduo" para percebermos que a literatura a esse respeito é vasta e controversa. Marcel Mauss situa sua origem no direito romano; Louis Dumont, seu discípulo, prefere os primórdios do cristianismo; outros autores consideram que as estruturas do individualismo teriam sido estabelecidas na Europa por volta do século XI (Mauss, 1968; Dumont, 1983; Morris, 1972). Mas faria sentido datá-la, como se houvesse um ponto inicial a partir do qual sua semente germinaria? A rigor, deveríamos dizer: no Renascimento emerge certa concepção do indivíduo, apenas isso (Burke, 1998). Sua história nada teria de contínua e linear, afinal as biografias e os autorrelatos não são o apanágio da mentalidade ocidental. Existem em outras sociedades inúmeros exemplos de um tipo de escrita intimista, psicológica, na qual a presença do Eu é imprescindível como artifício narrativo (Yamazaki, 1994; Ortiz, 2000). Por exemplo, no Japão, onde a literatura cortesã do século XI exprimia os sentimentos sufocados de um mundo privado. Contrariamente às narrativas épicas do Kojiki (712 d.C.), no qual se encontram as histórias fundamentais do xintoísmo (elas relatam, como nos mitos gregos, a saga dos deuses, não dos indivíduos), um romance como Genji Monogatari, revela uma sutil psicologia feminina ao descrever a vida cotidiana na corte Heian.

No entanto, as marcas do eurocentrismo não se restringem ao passado, elas mascaram o entendimento do presente. No caso de uma disciplina como a sociologia, as premissas anteriores marcam o conceito e o ideal de modernidade, e nela o indivíduo é figura central. Ele, na intimidade do seu Ser, é capaz de escolher sua orientação política, religiosa, seus amores, até mesmo suas vestimentas. Por isso os sociólogos da modernização afirmam que um dos traços operacionais da modernidade é sua capacidade de transformar a personalidade dos indivíduos, adequando-os a uma ordem social na qual os valores em relação às metas a serem atingidas tornam-se uma exigência coletiva e uma qualidade pessoal. Relembro, entre os inúmeros estudos realizados a partir dessa perspectiva, o livro de
Daniel Lerner sobre o Oriente Médio, The passing of traditional society. Sua definição de personalidade móvel é sugestiva:

A personalidade móvel pode ser descrita de maneira técnica e objetiva. A pessoa móvel distingue-se pela alta capacidade de identificação com o meio envolvente; ela está equipada com um conjunto de mecanismos necessários para incorporar as novas demandas que provêm de fora de sua experiência habitual. Esta é uma habilidade indispensável para as pessoas deixarem os seus territórios tradicionais (Lerner, 1958, pp. 49-50).

Dito de outra forma, somente assim os indivíduos poderiam fazer parte do mundo industrial, urbano, escolarizado e participativo (este é o diagnóstico do autor). Por isso o debate sobre a cultura de massa é tão importante para os teóricos da modernização. Jornais, rádio, televisão, filmes, teriam a propriedade de oferecer aos indivíduos uma gama de oportunidades, retirando-os da imanência dos costumes e integrando-os, de maneira igualitária (esta era a ideologia), ao todo social. $\mathrm{O}$ advento das novas formas de comunicação seria parte de um processo no qual a transformação contemplaria as estruturas econômicas, sociais e mentais das pessoas (cf., por exemplo, Lerner e Schramm, 1967). O dilema é que conceitualmente definida desta maneira, enraizada numa geografia particular, a modernidade somente poderia se atualizar via difusão, quando outras sociedades a reproduzissem em seu solo. Tornava-se imprescindível copiar o que havia se passado num mundo que lhes era inteiramente estranho. Afinal, o dualismo tradicional/moderno implicava um desnível civilizatório, e o surgimento da sociedade urbano-industrial exigia uma ruptura com o passado. A modernidade transforma-se, assim, em padrão para se interpretar o passado e, nos países periféricos, uma maneira de se ordenar o futuro. O conceito vinha imerso no fluxo de uma temporalidade progressiva e inexorável, marcadas por etapas a serem percorridas. Assim, a visão simplista e reducionista, de um autor como Rostow (1964), postulava que toda sociedade humana deveria necessariamente passar pelas seguintes fases de 
desenvolvimento: tradicional, take off (arranco para a industrialização), maturidade e, por fim, a era do consumo de massas. Certamente, sua compreensão nutria-se de um americanismo exagerado, pois nos anos de 1960 os Estados Unidos eram vistos como a única sociedade de massa digna de ser considerada como modelo. A definição que a International encyclopaedia of the social sciences faz do conceito de modernização é, também, exemplar: "Modernização é um termo atual para um processo antigo - o processo de mudança social no qual as sociedades menos desenvolvidas adquirem as características comuns às sociedades desenvolvidas”. Que características seriam essas:

1) um certo grau de crescimento econômico; 2) uma medida de participação pública, ou pelo menos uma representação democrática na definição e na escolha de políticas alternativas 3) a difusão de normas secular-racionais na cultura - compreendidas em termos weberiano-parsoniano; 4) um incremento da mobilidade na sociedade - entendida como liberdade de deslocamento físico e social, assim como de liberdade psíquica de movimentação; 5) uma correspondente mudança da personalidade modal que venha equipar, de maneira funcional e eficiente, os indivíduos para que possam operar de acordo com a ordem social com tais características (Lerner e Coleman, 1968, pp. 386 e 387).

O progresso gradativo emanciparia os países mais atrasados em relação ao tempo forte da modernidade. Haveria, inclusive, uma unidade de medida capaz de determinar se eles fariam ou não parte do grupo seleto das sociedades "avançadas". Bastaria aplicar o critério das características enunciadas na sua definição (segundo eles, tornava-se impossível compreender as revoluções russa e chinesa como elementos de modernização, afinal lhes faltaria a participação democrática). Esta obsessão pela mensuração espelha-se num conjunto de trabalhos que se dedicaram a estudos comparativos. Talvez o mais representativo seja o de Alex Inkeles e David Smith, Becoming modern (1974), no qual os autores tem a intenção de quantificar o curso da modernização em países como Argentina, Chile, Índia, Israel, Nigéria e Paquistão. Nesse sentido, a modernização seria um processo direcional de um estágio tradicional para o moderno, passando, na periferia, por um período de transição (tema debatido à exaustão pela literatura latino-americana).

A discussão sobre a modernidade apresenta-se, portanto, cada vez mais ambígua e imprecisa; uma vez aceitas suas premissas, tornava-se difícil escapar de suas armadilhas. Uma forma arguta de driblar os inconvenientes teóricos existentes foi proposta por Robert Bellah (1985), em sua análise da sociedade japonesa (cf. Morishima, 1987). De fato, o Japão sempre foi uma espécie de calcanhar de Aquiles dos teóricos da modernização. Como compreender o desenvolvimento de um pais oriental cuja revolução, Meiji, tinha sido feita em 1868? A rigor, seu processo de industrialização e de urbanização é contemporâneo ao da Alemanha e em muitos aspectos anterior ao de vários países europeus. $\mathrm{Na}$ virada do século, o Japão tinha se transformado numa potência militar e naval, havia vencido a guerra sino-japonesa (1894-1895), com a Rússia (1904-1905) e ensaiava seus primeiros passos imperialistas. Bellah considera que o período Tokugawa, momento no qual o confucianismo se transforma numa ideologia coletiva, é decisivo para a história japonesa. Os ensinamentos de Confúcio eram conhecidos no Japão desde o século VII, porém eles desfrutavam de pouca relevância diante da predominância do budismo. Somente com o fim das guerras "feudais" (1336-1573) e a ascensão da dinastia Tokugawa, o país se unifica em torno de uma mesma concepção de mundo. A sociedade estamental (samurai, camponeses, mercadores, artesãos) passa a se estruturar em torno de uma ética da lealdade ao "chefe", da família, da comunidade, da província, do governo militar. Cada estamento tinha sua especificidade: os samurais ocupavam-se da guerra e da administração; os camponeses, do cultivo da terra; os mercadores, das coisas do comércio; os artesãos, das construções e da fabricação de objetos. Os princípios confucianistas ajustavam os indivíduos à lógica particular dos grupos, mas pregava a todos os valores de frugalidade e submissão. A revolução Meiji rompe com os laços estamentais de um mundo em ruínas, mas recupera 
do confucianismo o princípio de lealdade, agora transferido para o plano do imperador, o "pai" da nação. Diligência no trabalho e abnegação às orientações industrialistas seriam elementos endógenos que explicariam o êxito do capitalismo nipônico. Apesar de engenhosa e instigante, a interpretação de Bellah tropeça numa questão espinhosa. Discípulo de Weber, ele se apropria de suas ferramentas teóricas para afirmar: o Japão modernizou-se graças a uma ética religiosa que cumpriu o mesmo papel do protestantismo no advento do capitalismo. Isso quer dizer que a modernidade poderia se reproduzir em lugares inóspitos a seu florescimento, desde que encontrasse algum sucedâneo válido para sua implantação. Evidentemente, esse tipo de raciocínio é problemático para se compreender a expansão da modernidade (na China o confucianismo assume papel inverso, vinculando-se às forças tradicionais) ou os distintos processos ocorridos na Ásia, no Oriente Médio, na América Latina, no mundo soviético. É preciso, portanto, romper o círculo vicioso no qual o argumento nos encerra e dizer sem hesitação: o modelo europeu, no qual os clássicos do pensamento sociológico se amparavam, tornou-se obsoleto. Por isso alguns autores começam a falar em modernidades-múltiplas. $\mathrm{O}$ plural é sugestivo, pois supóe que a matriz modernidade, em suas variações, se realiza historicamente de forma diferenciada; a realidade de cada lugar irá modelá-la de maneira distinta (Eisenstadt, 2000). Entretanto, se isso é verdadeiro, temos de dissociar a matriz de seu lugar de origem: o Ocidente. Se é possível dizer que ela surge em alguns países europeus com a Revolução Industrial, devemos acrescentar que em sua natureza ela não é ocidental. A matriz não se confunde com uma de suas versōes históricas, a europeia; esta é apenas a primeira cronologicamente, mas não a única, nem a sua forma é mais bem acabada. O tema do "atraso" pode ser reposto, pois a questão deixa de ser pensada em termos temporais. As comparações passam a ser feitas tomando como ponto de partida a diversidade dessas modernidades e não um ponto incerto no futuro no qual elas se espelhariam.

O debate sobre o eurocentrismo pode nos levar a uma série de mal entendidos. Talvez, o principal deles seja o relativismo. Diante da pertinência das críticas, a tentação seria de se considerar a herança iluminista como um discurso cultural do Ocidente. Levando-se a sério as lições da antropologia culturalista, deveríamos dizer: toda cultura é uma entidade singular, portadora de uma identidade. Nesse sentido, tendo em vista a singularidade da sociedade ocidental, as manifestaçôes culturais que ela encerra exprimiriam o seu "caráter". A argumentação apresentada é, no mínimo, contraditória. Primeiro, postula-se a existência de um espaço denominado Ocidente (quando se nega a existência de um Oriente). Sua concretude seria irrefutável, material, e não o resultado de um representação cuja história é perfeitamente possível de se reconstituir. A Europa, ou seja, o relato que dela se faz, deixa de ser uma entidade simbólica, imaginada, para se transformar numa realidade conjugada no singular, jamais no plural. Ela encerraria, na sua personalidade imanente, na sua essência, valores, disposiçōes espirituais, inclinações jurídicas e econômicas radicalmente distintos de todas as outras sociedades. Segundo, cultiva-se certo jdanovismo científico, no qual se opõe de forma antagônica uma ciência conspícua (burguesa, ocidental) à outra verdadeira (proletária, oriental). Retomo um velho termo do vocabulário da Guerra Fria, quando no campo soviético se propunha um tipo de abordagem dualista do mundo científico. Ele é expressivo, pois o relativismo contemporâneo, sem o saber (ninguém se recorda de um personagem inexpressivo como Jdanov), se inscreve dentro dessa perspectiva; ele irá, inclusive, multiplicar os diferentes pontos de vista (paradigma feminino, paradigma latino-americano, paradigma negro, paradigma nacional, paradigma ecológico, paradigma indígena etc.). Não se trata tampouco de buscar os equívocos dos filósofos das Luzes, como fazem alguns trabalhos quando denunciam, entre outras coisas, a indiferença em relação à barbárie da escravidão negra (ela existe e pode ser muito bem documentada; inclusive em Condorcet, cuja ambiguidade a respeito da abolição é patente). ${ }^{5} \mathrm{~A}$ rigor, sabemos que existe uma contradição entre os princípios abstratos de liberdade e o advento do capitalismo em escala planetária. $\mathrm{O}$ colonialismo e o imperialismo são invenções europeias, independentemente dos debates filosóficos em torno da perfeição do ho- 
mem universal. Mas a questão é outra. A tradição iluminista é uma herança, no sentido pleno da palavra, e dela fazemos parte. Uma herança não se recusa, ela possibilita, conforma e limita nossa reflexão. Possibilita, na medida em que a emergência das ciên cias sociais no século XIX, sua emancipação das injunçôes religiosas e políticas, se fazem em alguns países europeus (Alemanha, França, Inglaterra, mas não na Suécia ou na Espanha); conforma, pois o pensamento acadêmico encontra suas raízes e seus conceitos na continuidade deste legado; limita, pelo fato de ele exprimir um contexto particular, e não universal como nos queriam fazer crer seus artífices. Nesse sentido, a proposta de se "provincializar" esta Europa é extremamente significativa (Chakrabarty, 2000). O autor sublinha que tal herança é atualmente partilhada em escala mundial, porém temos tendência em considerá-la de maneira acrítica. Sua expansão deixa à sombra seus aspectos parciais: o fato de ela ter sido elaborada a partir de uma província do mundo. Territorializá-la, situá-la geograficamente na história, não significa abrir mão de uma vocação cosmopolita do pensamento; pelo contrário, a intenção é submetê-la às provas de uma reflexividade que ela mesma nos ensinou. Pierre Bourdieu (1997), particularmente em seus debates com filósofos, afirmava ser necessário historicizar a razão. As ciências sociais, ao ignorarem os seus fundamentos históricos, sofrem de uma espécie de amnésia das origens, esquecendo-se de que a universalidade das estratégias de universalização estão condicionadas por circunstâncias específicas. O "monopólio do universal" não é algo fortuito ou espontâneo, ele se ancora em grupos específicos, os cientistas sociais, que atuam em instituições universitárias e institutos de pesquisa; ele esconde, assim, os interesses daqueles que o enunciam. Nos termos de Bourdieu, para ilustrar meu argumento, eu acrescentaria, tal monopólio, entendido como sendo ocidental, se rompe na situação de globalização. Sua legitimidade como "registro de verdade" fragmenta-se. Nesse sentido, o mal-estar contemporâneo traduz menos os impasses do relativismo teórico, do que, sobretudo, as fissuras de um cânone a que se atribuía uma solidez ilusória.

Pode-se considerar essas mesmas questôes de um outro ângulo, o da internacionalização das ciências sociais. Do ponto de vista metodológico, como elas são ensinadas nos cursos universitários, as coisas seriam relativamente simples. Elas conquistam sua autonomia no final do século XIX, integrando um campo ordenado de problemas e técnicas de investigação, e constituem um legado que pode ser transmitido de geração em geração. Entretanto, sua história encerra inúmeros percalços. Um incidente exemplar é o mútuo desconhecimento de Durkheim e Weber. Há tempos, Tyriakian (1966) escreveu um pequeno texto buscando entender tal disparate. Sua interpretação é interessante. Os dois mestres tinham tudo para se conhecer. $\mathrm{O}$ interesse pela objetividade da pesquisa científica, a rejeição ao evolucionismo da época, a fundação de revistas especializadas para o desenvolvimento de pesquisas, o distanciamento em relação às explicações de cunho racial, eram preocupações suficientes próximas para colocá-los em contato. No entanto, eles se ignoram. Talvez o nacionalismo da época os tenha afastado, quem sabe o fato de Weber não ser considerado um sociólogo em seu tempo tenha induzido Durkheim ao equívoco, ou, ainda, ambos não consideravam importantes as contribuiçôes do outro para o desenvolvimento de suas próprias trajetórias - são as hipóteses de Tyriakian. Sua resposta, sempre no condicional, parte de um pressuposto. Como sublinha Michael Pollak (1986), ela postula a existência de uma comunidade científica universal nos moldes em que Merton a definia. A ciência seria uma instituição com regras e valores próprios, e seus atores agiriam de acordo com os princípios de seu funcionamento. Dessa perspectiva, o incidente representaria um desvio em relação à moral científica, cuja apreciação, em relação ao trabalho de outros membros da mesma comunidade, deveria ser menos egoísta (para Merton o comunismo era um dos princípios da ética científica). Apesar das observações de Pollak, que me parecem corretas, minha impressão é que a resposta de Tyriakian, embora insuficiente, é emblemática. A crença na existência de uma instituição universal, acima do contexto histórico, é partilhada por vários autores; e por um bom tempo as ciências sociais foram transmitidas dentro deste padrão. Retomo um texto de Edward Shils no qual traça um retrospecto da sociologia. Ele afirma que até meados de 1930 o 
panorama sociológico era desanimador: na França, na Alemanha, na Inglaterra e nos Estados Unidos, existiam estudos esparsos, desconexos, fragmentados, sem nenhuma unidade entre si. O impulso dos princípios de uma teoria sociológica, herdeira dos ensinamentos de Weber e Durkheim, tinha praticamente declinado. Mas ele acrescenta: "The structure of social action foi um divisor de águas. Foi este trabalho que conseguiu integrar a tradição parcial numa mesma unidade de medida" (Shils, 1965). Por isso o subtítulo de seu texto: "Da heterogeneidade à unidade". A visão de Shils é americano-cêntrica: Talcott Parsons seria o epígono da unidade teórica à deriva. Entretanto, ela se tornou um senso comum universitário, certamente devido à expansão e ao predomínio da sociologia norte-americana, na época hegemônica em diversas partes do mundo.

Isso possui algumas implicações. Como o desenvolvimento das ciências sociais nos países periféricos foi tardio, após a Segunda Guerra Mundial, ele coincidiu com o momento em que a certeza de sua unidade teórica se impôs. É o caso da América Latina. No Brasil, Florestan Fernandes, e na Argentina, Gino Germani, representam esta fase de implantação da disciplina. Dois livros são expressivos desse período, Fundamentos empiricos da explicação sociológica (1959) e La sociologia cientifica: apuntes para su fundamentación (1956). Ambos se ocupam de questôes de método e tem por ambição desenvolver um pensamento sociológico rigoroso, "científico", distinto de um certo ecletismo ainda predominante (Ianni, 1986; Blanco, 2006). Essas datas são expressivas quando comparadas aos caminhos da sociologia em outros lugares. Durkheim funda o L'Année Sociologique em 1897, Weber era editor do Archivfur Sozialwissenshaftund Sozialpolitik (1904) e o departamento de Sociologia da Universidade de Chicago foi criado em 1892. As ciências sociais latino-americanas encontravam-se defasadas e deveriam se ajustar ao tempo de suas matrizes principais, norte-americana ou europeia. Não é casual que o debate sobre o padrão do trabalho científico se faz concomitantemente em diversos países, sem que seus participantes estejam necessariamente em contato. Isso fica claro nas discussōes que Florestan Fernandes (1977) e Gino Germani (1964) têm com seus adversários "nacionalistas". Eles de- fendem a consolidação de um saber estritamente "científico" em contraposição à proposta da sociologia como conhecimento de "salvação nacional". O que lhes interessa é um tipo de formação intelectual condizente com as normas, os valores e os ideais do saber científico (como pensavam Merton e Manheim: a ciência seria uma subcultura orientada por um ethos específico). A polêmica pode ser interpretada de várias maneiras; na época, ela polarizou as posiçóes em torno do contraponto entre ciência e ideologia, sendo inúmeras as críticas aos autores pelo seu cientificismo (Veron, 1972). Mas ela é emblemática, pois cada um deles, à sua maneira, reage à mesma situação estrutural: garantir um estatuto acadêmico à uma prática ainda incipiente. Nesse sentido, a identidade da nova disciplina via-se, impreterivelmente, diante do dilema da transplantação das ideias, pois sua afirmação se fazia no terreno predeterminado do próprio conhecimento sociológico. Poderiam os "esquemas abstratos de análises", elaborados num determinado contexto serem aplicados a uma outra realidade? Qual seria sua validade conceitual? Essas eram as perguntas que animavam o debate intelectual. Porém o contraste com o alter-ego europeu ou norte-americano não era somente uma miragem ideológica (como diziam os críticos do colonialismo intelectual), mas uma condição estrutural que envolvia o campo das ciências sociais como um todo. Dois aspectos merecem ser sublinhados neste processo.

Primeiro, uma tensão constante em relação à modernidade, pois os modelos disponíveis se mostravam inadequados para entender uma situação distinta. Florestan Fernandes depara-se com o desafio de construir uma interpretação do Brasil moderno, levando-se em consideração a absorção da mão de obra escrava numa sociedade de classes. Mesmo Gino Germani, que pode ser considerado um expoente da teoria da modernização (é suficiente consultar seu livro Sociologia de la modernización), não se sente à vontade dentro da exiguidade de seu quadro teórico; ao interpretar o peronismo, vê-se obrigado a estabelecer uma nítida distinção entre o que se passa na Argentina e as experiências europeias de totalitarismo. Isso é uma constante no seio da intelectualidade latino-americana. Mariátegui, em seus escritos sobre o Peru, debate-se com um pro- 
blema semelhante. Ele quer, a partir do marxismo, entender uma realidade determinada, a questão indígena, utilizando-se de um arcabouço teórico em que ela estava ausente (Quijano, 1991). Era pois necessário se apropriar de um método estrangeiro, orientando-o noutro sentido. A compreensão da modernidade periférica tornava-se, portanto, cada vez mais problemática. $\mathrm{O}$ hiato entre um modelo ideal e a presença dos fenômenos sociais acentuava a distância entre pensamento "local" e pensamento "universal". Um exemplo eloquente é a crítica que os teóricos da dependência fazem aos padrões sociológicos norte-americanos. A discussão sobre o desenvolvimento, caracterizando as sociedades como desenvolvidas ou subdesenvolvidas e as fases de transição para a modernidade, adquire, assim, uma dimensão teórica, não se limitando às questões de natureza política e econômica (evidentemente, também relevantes). Esta é a ambição do ensaio de Fernando Henrique Cardoso, "Originalidade da cópia”, em que analisa o pensamento da Cepal (Cardoso, 1980). Contrário à importação de determinados modelos de explicação, ele queria entender as ideias em "seu lugar", isto é, como elas são reelaboradas em contextos específicos, sendo originais e distintas das propostas da metrópole. Para isso era importante reconhecer que o processo de realização da modernidade envolveria algumas especificidades, ausentes do contexto europeu. E que no plano do pensamento seria possível pensá-las não como desvio, defasagem, mas como as considera Martin-Barbero (1998), "uma diferença que não se esgota no atraso".

Segundo, a consolidação das ciências sociais se faz por via da questão nacional que norteia o horizonte das perguntas metodologicamente pertinentes. Na verdade, é impossível entendê-las fora deste quadro mais amplo. Como na Europa, o século XIX na América Latina foi o século das naçôes. Entretanto, se em países como França, Inglaterra e Alemanha sua emergência encontra-se intimamente associada à consolidação da modernidade, tem-se, no caso latino-americano, uma dissociação temporal desses dois movimentos. Sonha-se com uma revolução industrial, que só irá se concretizar no século XX, momento em que efetivamente as sociedades latino-americanas se modernizam. Há, pois, um hiato entre o ideal perseguido e a realidade inconteste. Cada país, ao imaginar sua identidade, tem como referência o que se passa em parte da Europa ou nos Estados Unidos. A imagem refletida no espelho será sempre distorcida. Na realidade almeja-se aquilo que ainda não se é. Mesmo com as transformações ocorridas no início do século XX reforma agrária (revolução mexicana), urbanização, racionalização do aparelho de Estado, redefinição da noção de trabalho numa sociedade oligárquica e servil - esta sensação de atraso persiste. A modernidade é um projeto, uma utopia, algo que pertence ao porvir. Este é o dilema, os Estados nacionais devem construir o que ainda não possuem. Por isso o modernismo latino-americano é distinto do europeu. Nos países industrializados a questão da forma artística equivalia à sua adequação às mudanças sociais. $\mathrm{O}$ mundo da Revolução Industrial exigia do artista a reformulação de suas ideias. $\mathrm{O}$ impressionismo e o art-nouveau correspondiam à realidade que os envolvia, traduzindo a materialidade dos "mecanismos da vida moderna" (luz elétrica, bondes, sistema ferroviário, automóveis, a efervescência cultural das metrópoles). ${ }^{6}$ Faltava no continente latino-americano justamente esses elementos. $\mathrm{O}$ modernismo existe, mas sem modernização. Os artistas tinham a intenção de ser modernos, mas suas propostas eram ainda uma projeção (como os muralistas mexicanos ou o manifesto antropofágico de Oswald de Andrade). Eles se distanciavam, assim, do ideal flaubertiano da arte pela arte, pois o componente político da nação atravessa o universo artístico. Arte e política são termos complementares - o artista é sempre um intelectual "engajado" na busca da modernidade. Pode-se dizer o mesmo dos debates em torno da modernização e do desenvolvimento em voga nos anos de 1950 e 1960. Quando seus porta-vozes afirmavam, "sem uma ideologia do desenvolvimento não há desenvolvimento", o que se reiterava era a anterioridade do projeto em relação ao subdesenvolvimento existente. Cito Álvaro Vieira Pinto, representante paradigmático deste tipo de pensamento:

[...] a falta da tomada de consciência objetiva da nossa realidade, por parte de nossos melhores homens, priva-os de percepção histó- 
rica segura e global, desnorteando-os, o que contribuiu para o atraso do nosso processo de desenvolvimento, pois não há interpretação sem categorias prévias de interpretação. [E ele acrescenta:] [...] devemos conhecer o desenvolvimento como um processo que encontra sua definição na finalidade a que se dirige. Não se trata do conceito vago e impreciso de finalidade em geral, mas de finalidade rigorosamente fixada e lucidamente compreendida, pois sem a clareza e a exatidão dos fins visados, o processo não poderia se constituir (1959, pp. 15 e 25).

Caberia aos intelectuais tomar consciência desta situação de precariedade e traçar uma linha de ação para superá-la. As ciências sociais não escapam a este destino. Os temas que elas trabalham miscigenação, urbanização, industrialização, questão indígena, reforma agrária - vêm marcados pela presença do que se convencionou nomear "a questão nacional".

Eu havia dito que a difusão internacional das ciências sociais, do ponto de vista disciplinar, se faz pela afirmação de sua unidade metodológica. No entanto, nos países periféricos elas adquirem uma feição regional: enfrentam problemas considerados temporalmente deslocados em relação aos países centrais e se consolidam em estreito diálogo com a problemática nacional, o que acarreta ambiguidade ao campo sociológico. Existiria, pois, um padrão único (universal) praticado pelos europeus e norte-americanos que traduziria de maneira inequívoca as exigências de uma ciência da sociedade. Em contrapartida, fora de suas fronteiras, tal padrão se desdobraria em duas vertentes: uma metodológica (comum à disciplina como um todo), outra específica, configurando-se como um saber enraizado em conjunturas regionais. Isso fica claro na distinção proposta por Tyriakian entre "grande" e "pequena" tradição sociológica. A primeira constituiria o eixo da disciplina, em torno do qual se estruturariam os problemas e os argumentos centrais do conhecimento e da pesquisa. Por uma coincidência fortuita, o solo da "grande tradição" corresponderia ao pensamento clássico europeu e norte-americano. Restaria à "pequena tradição" um papel mais modesto. Conforme o autor:
[...] vários eixos nos quais as tradiçõos de menor magnitude do que aquelas exigidas em nossas profissōes podem ser apontados. Um desses eixos, frequentemente utilizado, explícita ou implicitamente, diz respeito ao contexto do desenvolvimento nacional da sociologia. A sociologia como ciência da sociedade é um pressuposto que favorece uma perspectiva universal de seu quadro teórico e conceitual; mesmo assim, na maioria dos lugares ela se desenvolve segundo o contexto nacional, no qual um treinamento gradual é oferecido (Tyriakian, 2001, p. 15827).

A internacionalização das ciências sociais se faria, portanto, através do modelo de difusão: quanto mais acentuada sua expansão, mais participantes se integrariam a elas (daí a necessidade de serem "treinados"). Surge, assim, o problema da "indigenização", da aclimatação das ideias e das técnicas de pesquisa em lugares distantes do padrão de origem. ${ }^{7}$ As versōes nacionais atestariam o desenvolvimento de determinado saber em escala global, mas a bifurcação entre as tradiçōes - uma legítima, outra menos - confirmaria o fosso existente entre elas. A partir dessa diferenciação tácita, certa divisão internacional do trabalho intelectual instaura-se. As verdadeiras reflexôes de caráter teórico seriam uma primazia do "Ocidente", não tanto por motivos ideológicos, simplesmente porque ali se encontraria o núcleo da modernidade, suas estruturas profundas. A defasagem temporal impossibilitaria aos pensadores latino-americanos ou asiáticos atingir o seu âmago. Com efeito, qualquer estudo sobre a modernidade periférica seria incompleto, faltando-lhe a densidade negada pela história. Malgrado sua pertinência, as críticas à teoria da modernização não serão ouvidas, cairão no terreno do esquecimento (elas foram escritas em idiomas nativos e não na língua da modernidade-mundo, o inglês). Além disso, o fato de as ciências sociais estarem mescladas à temática da nação acentuava sua coloração local diante das exigências de universalização. Para se libertar da opressão intelectual era preciso valorizar as próprias raízes; este é o dilema que atravessa todo o "pensamento latino-americano". Basta lermos os escritos de Leopoldo Zea (1965) para nos 
darmos conta de que a emancipação intelectual se faz via afirmação nacional. Este é o passo inicial, a ruptura que permite a construção de um referencial teórico isento das contradições conceituais elaboradas na metrópole.

Entretanto, o traço de união - América Latina - tinha pouca consistência e se desfazia quando considerado à luz das especificidades de cada lugar. O surgimento das ciências sociais não se fez a partir do marco latino-americano, mas das particularidades de cada nação. Por exemplo, no Brasil, no final do século XIX e início do XX, a introdução das ideias sociológicas se faz pela influência europeia. Particularmente Comte, Spencer, tardiamente Durkheim; há pouco contato com o universo alemão. Não se trata, contudo, de uma especialização disciplinar; as elites brasileiras evoluem em torno das instituições tradicionais criadas durante o Império: faculdades de direito, escolas de medicina, institutos históricos e geográficos. O debate principal centra-se na identidade nacional; procurava-se entender que futuro teria um país resultante da mistura de raças tão díspares: negra, indígena, branca. Este é o desafio intelectual para escritores como Silvio Romero, Nina Rodrigues e Euclides da Cunha (Ortiz, 1985). Como mostra Carlos Altamirano (1988), há algo similar na Argentina. A preocupação com a construção nacional e a questão racial é também uma constante. Os diagnósticos elaborados em livros como Nuestra América (1903), de Carlos Bunge, ou La evolución sociológica argentina (1910), de José Ingenieros, discutiam como seria possível a melhoria das raças através da imigração europeia. Como no Brasil, e no resto da América Latina, o pensamento raciológico e racista exercia o seu fascínio.

Entretanto, a situação argentina era diversa. Sua industrialização antecedeu em décadas a brasileira e, devido à importância da imigração, que abarcava setores intelectualizados, o contato com as ideias europeias era mais amplo e diversificado (um autor como Simmel foi lido muito precocemente). Isso faz com que no interior de algumas faculdades de direito sejam criadas cátedras de Sociologia: La Plata (1904), Córdoba (1907), Buenos Aires (1908). Na Argentina, contrariamente ao que ocorreu no Brasil, onde o debate racial perdura até a Re- volução de 30, o panorama é outro. Desde o início do século XX o pensamento sociológico (mesmo eclético e distante das pesquisas empíricas), juntamente com o problema racial e a assimilação dos imigrantes, incorpora um tema novo: a modernização capitalista. A questão nacional, na qual se inscrevia o destino do país, tomava uma configuração distinta. O pensamento latino-americano subdividia-se, portanto, em unidades menores: brasileiro, mexicano, argentino, chileno. A história das ciências sociais é narrada no plural, não no singular: sociologia brasileira, sociologia peruana, sociologia mexicana etc. Aspecto que acirra a contradição entre o autóctone e o estrangeiro, pois toda identidade contém uma dupla face: ela delimita um espaço interior (moradia da autenticidade) e o separa do que the seria estranho.

O problema, neste caso, é que o estranho correspondia ao que se esperava conquistar: a autonomia do padrão sociológico. A busca da identidade acadêmica terminava num impasse. Ela se enredava na teia de uma sutil hierarquia, na qual o nacional, sendo específico à cada localidade, lhe cerceava o caminho da generalização. A rigor, não faria sentido falar na existência de um pensamento francês ou alemão, pois Durkheim e Weber seriam "universais"; Parsons tampouco poderia ser identificado como norte-americano, ele era o autor de $A$ estrutu$r a$ da ação social. Apenas na periferia a arte da reflexão podia ser qualificada, ambígua e positivamente, desta maneira. Construiu-se certo consenso, ou se preferirem, uma regra cortês de convivência internacional, na qual a universalidade do método era uma prerrogativa de alguns e sua aplicação disponível a todos. O movimento de expansão das ciências sociais vinha marcado pela duplicidade. De um lado, ele revelava uma real consolidação dos métodos e das análises de uma disciplina acadêmica - criação de cursos universitários, fundação de institutos de pesquisa, interação cada vez maior entre os pesquisadores. Esta vocação internacional manifesta-se desde o século XIX. Vários autores sublinham ser este o momento em que surge um tipo de organização e de atividade inexistente na antiga república das letras: as conferências científicas internacionais e as associações científicas internacionais. Movimento que atravessa o campo científico 
e se intensifica com a especialização das disciplinas [Institut International de Sociologie (1893); Congrès Historique International (1898)]. A criação dessas entidades acelerará o fluxo transnacional das redes de pesquisadores e incentivará a busca de uma língua universal de comunicação entre os cientistas (Rasmussen, 1996). Elas irão se proliferar, sobretudo ao longo do século XX: International Union of Anthropologica land Ethnological Science (1934); International Sociological Association (1949); International Political Science Association (1949); Facultad Latinoamericana de Ciências Sociales (1957) (Heilbon, Guilhot e Jeanpierre, 2009). Após a Segunda Guerra Mundial, um organismo como a Unesco passa a financiar diversas dessas associaçôes internacionais, incentivando a pesquisa e os intercâmbios científicos (por exemplo, a pesquisa sobre o negro realizada no Brasil por Roger Bastide, Florestan Fernandes, Costa Pinto, Thales de Azevedo). Não obstante, subjaz à este desdobramento a incerteza do particular. Na periferia a prática sociológica conjugar-se-ia no plural devido às tradições nacionais. A tensão entre o universal $\mathrm{e}$ o diverso resolve-se, dessa forma, em favor de uma desclassificação dos outros; ela reforça a ilusão de um modelo único cuja realidade repousa, menos na sua consistência teórica do que na assimetria existente entre países e instituições acadêmicas.

Este quadro transforma-se radicalmente na situação de globalização. A emergência de noções como "modernidades múltiplas", o advento de uma literatura pós-colonial, a criação de subáreas de conhecimento como os estudos culturais, a valorização da interdisciplinaridade como forma de avançar o conhecimento, assim como a crítica ao eurocentrismo, deixam-nos diante de um mapa heterogêneo das ciências sociais. Basta lermos o relatório organizado pela Comissão Gulbenkian sobre sua reestruturação para nos darmos conta de que a prática sociológica se distanciou de seu passado clássico (Wallerstein, 1996). Seu desenvolvimento nos países ditos periféricos, orientais, atrasados, rompe o vínculo orgânico entre os pais fundadores e os lugares nos quais o pensamento sociológico emergiu: França, Alemanha, Inglaterra e Estados Unidos. Ao provincializá-lo, isto é, circunscrevê-lo a um determinado espaço, percebemos sua evolu- ção de outra maneira. O surgimento de universidades, institutos de pesquisa, políticas de incentivo à ciência, em diferentes países do mundo, tende, senão a nivelar a concorrência entre esses centros, pelo menos a debilitar as certezas anteriores. Fica difícil sustentar a crença de um padrão único da prática sociológica. O debate sobre a existência de "uma" ou "várias" sociologias, a despeito de qualquer intenção teórico-metodológica, torna-se inelutável (Sztompka, 2010). Afinal, cada localização espacial conferiu uma coloração diversificada à sua internacionalização. A defasagem que os autores latino-americanos ressentiam é assim substituída por um conjunto de tradições intelectuais que se complementam e diferem entre si.

De outro lado, a ideia de nação adquire nova feição; o processo de globalização coloca em xeque sua centralidade no âmbito das relações sociais, políticas e econômicas. Entretanto, a "crise" do Estado-nação não se circunscreve a temas como soberania ou meio ambiente, ela é também categorial; como unidade de análise, o Estado-nação torna-se um conceito insuficiente para se compreender a abrangência da modernidade-mundo. Como observa Octávio Ianni:

[...] se as ciências sociais nascem e desenvolvem-se como formas de autoconsciência científica da realidade social, pode-se imaginar que elas podem ser seriamente desafiadas quando essa realidade já não é mais a mesma. $\mathrm{O}$ contraponto de pensamento e pensado, ou de lógico e histórico, pode-se alterar-se um pouco, ou muito, quando um dos termos modifica-se; e mais ainda quando ele se transfigura (1993. p. 171).

A situação de globalização requer das ciências sociais uma reavaliação de sua herança intelectual. Diante das transformações ocorridas, muitos de seus conceitos, cunhados no final do século XIX, tornam-se inapropriados: não se deve esquecer que as controvérsias entre indivíduo e sociedade, o padrão de soberania para a ciência política, e mesmo de mercado para a economia, fundamentavam-se em processos e estruturas nacionais. Mas quais seriam as consequências dessas mudanças para o pensamento sociológico? Gostaria de sublinhar pelo 
menos duas: primeiro, a necessidade de se imaginar novas categorias para a compreensão da modernidade-mundo (tema fartamente discutido na literatura sobre a globalização); segundo, aspecto que interessa diretamente à minha argumentação, os intelectuais europeus e norte-americanos, diante da radicalidade das transformações, devem repensar a trajetória do conceito de nação (particularmente com a consolidação da União Europeia). Diversos estudos, revisitando a emergência das ciências sociais como um saber autônomo, passam, agora, a insistir na ideia de tradição intelectual nacional.

Donald Levine (1997), por exemplo, identifica diferentes tipos de tradições: britânica, francesa, alemã, italiana e norte-americana (o marxismo, com sua vocação internacionalista, é a única exceção). Os sociólogos britânicos cultivam uma visão individualista e evolucionista, combinada a uma preocupação constante com a mensurabilidade. Assim, para um autor como Smith as inclinaçôes individuais são os princípios explicativos dos fenômenos sociais (mercado) e o fundamento da moralidade humana, critério para a definição do bem social. A tradição francesa toma uma outra configuração, enfatizando a dimensão holística do social, o todo prevalecendo sobre as tendências individuais. É neste sentido que podem ser compreendidas as críticas de Durkheim a Mill e Spencer, quando esses autores apreendem os fatos sociais como algo decorrente das motivaçôes atomizadas dos indivíduos. Por isso é possível falar numa tradição francesa de crítica da economia política (Steiner, 2008). O mesmo pode ser dito da especificidade norte-americana, seu caráter decididamente empírico, ou alemã, que se centra no sujeito que interpreta o social, é capaz de autodeterminação, sabe discriminar e escolher segundo critérios morais bem definidos. Cada uma dessas tradiçôes constitui um ponto de partida para se construir uma pluralidade de problemáticas teóricas que virão, posteriormente, constituir o legado clássico da sociologia. Estamos distantes de uma proposta como a de Nisbet (1967), na qual as ciências sociais seriam estruturadas a partir de um núcleo central de ideias: comunidade, sagrado, autoridade, status, alienação. Este seria o eixo principal do interesse sociológico, conhecimento que se estrutura e se cristaliza no período formativo da disciplina (1830-1900). Teríamos, assim, a consolidação de um padrão único, a questão seria apenas de difundi-lo em escala internacional.

Mas a marca do nacional não se restringe ao plano das ideias. $\mathrm{O}$ processo de institucionalização das ciências sociais é fortemente influenciado pela relação com os Estados nacionais. Como pondera Peter Wagner: "Quanto mais as questōes levantadas nas ciências sociais são definidas num país determinado em reação à ordem sociopolítica estabelecida, mais o seu caráter nacional é pronunciado" (2004, p. 61). Isso ocorre na Itália com processo de unificação do país, na França com a ideologia republicana e também na Alemanha. Torna-se claro, nessa perspectiva, o papel do Estado na conformação das disciplinas acadêmicas (análises estatísticas, formação de quadros profissionais, criação de universidades) (Wagner, Wittrock e Whitley, 1991). Mas como suas demandas são diferentes, em cada lugar a institucionalização adquire aspecto diversificado. A imagem que Shils apresentava do conhecimento sociológico perde força e poder de convencimento, sua nitidez é atenuada, deixando à sombra dúvidas e incertezas. Temos hoje a clara consciência de que o chamado período clássico da sociologia conheceu uma série de tentativas frustradas de institucionalização; em função das questôes políticas, sociais e econômicas, o projeto sociológico fragmentou-se segundo sua inclinação local. Cabe lembrar que Weber tinha inúmeras restrições em denominar-se sociólogo; somente após a criação da Sociedade Alemã de Sociologia, em 1909, é que ele passa a aceitar, com relutância, tal rótulo. $\mathrm{Na}$ verdade, como sugere Bourdieu, as ciências sociais evoluem nos espaços nacionais porque a constituição de um campo de práticas acadêmicas se encontra vinculada às condiçôes históricas que possibilitam sua existência. Elas pressupõem a existência de um espaço intelectual no qual os agentes (com trajetórias individuais distintas) atuam em instâncias específicas (revistas, universidades, institutos de pesquisa) proporcionadas por políticas educacionais e científicas bem determinadas (distribuição de recursos, incentivo à educação superior, criação de laboratórios etc.). A autonomia deste território, isto é, as condições políticas, sociais e econômicas 
em que ele funciona, é sempre relativa e variável. Sua heterogeneidade traduz as possibilidades reais existentes em cada lugar. $\mathrm{Na}$ realidade, quando se lê os clássicos, percebe-se que possuíam uma nítida consciência da dimensão nacional de seus empreendimentos (Heilbron, 2008). Durkheim, mesmo após ter retornado de sua viagem à Alemanha, onde toma contato com uma literatura rica e exuberante sobre a vida social, não hesita em definir a sociologia como uma ciência francesa. $\mathrm{O}$ balanço que ele faz do seu desenvolvimento é inequívoco: "Determinar a parte que diz respeito à França no progresso da sociologia durante o século XIX é fazer em grande parte a história desta ciência, pois foi entre nós, no curso do século XIX, que ela nasceu, permanecendo assim uma ciência essencialmente francesa" (Durkheim, 1987, p. 111). Os sociólogos norte-americanos também estavam imbuídos de que seus escritos representavam as virtudes de um país excepcional (Ross, 1991). A revolução norte-americana e o governo republicano, sendo autóctones, alimentavam um contraponto idealizado em relação à Europa, onde a modernidade estaria minada pela pobreza e o conflito de classes. A ideologia liberal (todos seriam iguais), a ênfase no individualismo, que se torna uma marca de suas ciências sociais, ancorava-se numa concepção de mundo que a diferenciaria dos pensadores europeus. Esta percepção da relação orgânica entre as ciências sociais e o nacional, tão viva em sua época, terminou por ser sublimada, sendo substituída por uma visão mais neutra e homogênea do mundo científico. A reconstrução atual de sua história realça um aspecto antes considerado atributo das modernidades incompletas. Nesse sentido, a especificidade do nacional, vista antes como um entrave ao conhecimento, não seria uma dimensão exclusiva das realidades periféricas, o que faz com que a pretensa distinção entre universal (Estados Unidos e Europa) e particular (o restante do mundo) se torne cada vez mais questionável. A história das ciências sociais deixa de ser pensada segundo a matriz difusionista, exportação da metrópole para a periferia, dando lugar a um quadro bem mais complexo de sua constituição transnacional.

Em O raciocinio sociológico, Jean Claude Passeron observa que a língua sociológica, contrariamente às ciências lógico-matemáticas ou da nature- za, nunca conseguiu atingir equilíbrio, mesmo que precário, para definir as ciências sociais como uma ciência normal (nos termos de Khun). Seu estado "caótico", impreciso, demonstra a dificuldade constitutiva de um saber que se realiza sempre em contexto. Isso não significa que ele tenha de renunciar a todo e qualquer tipo de generalização. Pelo contrário, as pesquisas empíricas acumulam um rico conhecimento que nos permite, através do esforço comparativo, escaparmos das malhas de cada província. Entretanto, tais generalizações encontram-se distantes do ideal popperiano de cientificidade. Quero reter de Passeron não tanto seus argumentos de ordem metodológica, mas a metáfora por ele utilizada para caracterizar o discurso sociológico: a língua. Ela é sugestiva e nos auxilia a apreender algumas dimensōes relativas à diversidade das interpretaçōes. Recordo ao leitor a distinção que os linguistas fazem entre linguagem, que nos remete à ideia de universal, e língua, sua atualização na história. Eu havia mencionado a ambiguidade que imperava a respeito de um único padrão da prática sociológica. Creio ser possível caracterizá-la como uma tentação em se pensar o idioma das ciências sociais como linguagem. $\mathrm{O}$ estatuto de sua universalidade estaria, assim, garantido. Haveria uma conjunção feliz entre as exigências de natureza epistemológica e o padrão inaugurado pelos clássicos. $\mathrm{O}$ panorama atual torna esta visão das coisas um tanto irênica: sem conflitos. De fato, a noção de linguagem é imprópria para descrever o discurso das ciências sociais, sendo melhor recorrermos à de língua, uma vez que incorpora as dimensōes de história e o contexto. Surge, então, uma questão perturbadora. Os linguistas ensinam que toda língua, em função de sua disseminação no espaço e no tempo, conhece uma série de variaçōes, por exemplo os dialetos. Seria o destino das ciências sociais se fragmentar em províncias dialetais cada uma delas com fronteiras claras e excludentes? Esta interrogação traduz de forma inquietante o mal-estar do universalismo ao qual eu me referia antes. Uma maneira ilusória de se resolver tal problema seria retomar um antigo debate sobre a existência de um único padrão (standard) linguístico. Ou seja, a língua padrão, normatizada pelos gramáticos, unificaria a diversidade das falas. Esta é, porém, uma solução artificial pois o padrão 
postulado não possui nenhuma realidade empírica, ele é simplesmente um constructo imaginado por aqueles que o elaboraram. Mas não nos esqueçamos, toda língua possui, também, diferentes sotaques, sem que isso venha constituir em falas incomunicáveis entre si. Penso ser possível dizer que o idioma das ciências sociais é compartilhado por uma mesma comunidade de falantes, mas seus sotaques são distintos. Ao se atualizar em lugares afastados, ele guarda sua vocação cosmopolita sem perder a diversidade que o constitui. A conversa entre os cientistas sociais pressupõe, assim, duas dimensôes complementares: um universo comum e o esforço da tradução dos sotaques.

\section{Notas}

1 Para uma crítica ao "direito de intervenção" dos países ocidentais, ver Wallerstein (2006).

2 A literatura sobre o tema é imensa. Ver, entre outros, Asad (1973).

3 Ver, por exemplo, Landes (1999). O autor dedica todo um capítulo ao "European exceptionalism".

4 Jack Goody faz uma boa discussão das premissas weberianas em seu livro The east in the West (1996).

5 Refiro-me a um texto como o de Louis Sala-Moulins, Les misères des lumières (2008); consultar, ainda, Delacampagne (2002).

6 Utilizo uma expressão cara a um cronista do século XIX, Georges d'Avenel.

7 O livro de Nikolai Genov (1989), elaborado sob os auspícios da Internacional Sociological Association (ISA), estrutura-se a partir desta ideia falaciosa da "indigenização" das ciências sociais.

\section{BIBLIOGRAFIA}

ALTAMIRANO, Carlos. (1988), "Entre el naturalismo y la psicología: el comienzo de la 'ciencia social' en la Argentina”. Conferência apresentada na Anpocs, Caxambu, MG.

AMIN, Samir. (1988), L'eurocentrisme. Paris, Anthropos.

ASAD, Talad (ed.). (1973), Anthropology \& the colonial encounter. Londres, Ithaca Press.
BELLAH, Robert. (1985), Tokugawa religion: the cultural roots of modern Japan. Londres, Free Press.

BERNAL, Martin. (1987), Black Athena: the fabrication of ancien Greace 1785-1985. New Brunswick, Rutgers University Press.

BLANCO, Alejandro. (2006), Razón y modernidad: Gino Germani y la sociologia en la Argentina. Buenos Aires, Siglo XXI.

BLAUT, J. M. (1993), The colonizer's model of the world: geographical diffusionism and eurocentric history, Nova York, The Guilford Press.

BOURDIEU, Pierre. (1997), Méditations pascaliennes. Paris, Seuil.

BURKE, Peter. (1998), The European renaissance: centres and peripheries. Oxford, Blackwell.

CARDOSO, Fernando Henrique. (1980), "Originalidade da cópia: a Cepal e a ideia de desenvolvimento", in As ideias e seu lugar, Petrópolis, Vozes.

CHAKRABARTY, Dipesh. (2000), Provincializing Europe. Princeton, Princeton University Press.

DELACAMPAGNE, Christian. (2002), "Une ombre sur les lumières", in , Une histoire de l'esclavage, Paris, Le Livres de Poche.

DUMONT, Louis. (1983), Essais sur l'individualisme. Paris, Seuil.

DURKHEIM, E. (1987), "La sociologie en France au XIX siècle”, in _ La science sociale et l'Action, Paris, PUF.

EISENSTADT, S. N. (2000), "Multiple modernities". Daedalus, 129 (1).

FANON, Franz. (1961), Les Damnés de la terre. Paris, Maspero.

FERNANDES, F. (1977), "O padrão do trabalho científico dos sociólogos brasileiros”, in , A Sociologia no Brasil, Petrópolis, Vozes.

FERNÁNDEZ-ARMESTO, Felipe. (1996), Milênio: história dos últimos 1000 anos. Lisboa, Presença.

GELLNER, Ernest. (1985), Relativism and the social sciences. Cambridge, Cambrige University Press.

GENOV, Nikolai (ed.). (1989), National traditions in sociology. Londres, Sage.

GERMANI, Gino. (1964), La sociologia en América Latina. Buenos Aires, Eudeba. 
GOODY, Jack. (1996), The East in the West, Cambridge, Cambridge University Press. . (2006), The theft of the history. Cambridge, Cambridge University Press.

HEILBRON, Johan. (2008), “Qu'est-ce qu'une tradition nationale en sciences sociales?". Revue d'Histoire des Sciences Humaines, 1 (18).

HEILBRON, J.; Guilhot, N. \& Jean-Pierre, L. (2009), "Vers une histoire transnationale des sciences sociales". Sociétés Contemporaines, 1 (73).

HOBSON, John Atkinson. ([1962] 1968), Imperialism: a study. Londres, George Allen \& Unwin.

HOBSON, John M. (2004), The Eastern origins of Western civilization. Cambridge, Cambridge University Press.

IANNI, Octávio. (1986), "Florestan Fernandes e a formação da sociologia brasileira", in Florestan Fernandes: sociologia, São Paulo, Ática. . (1993), A sociedade global. Rio de Janeiro, Civilização Brasileira.

INKELES, Alex \& Smith, David. (1974), Becoming modern. Londres, Heinemann.

LANDES, David. (1999), The wealth and poverty of nations. Nova York, Norton.

LERNER, Daniel. (1958), The passing of traditional society. Nova York, The Free Press.

LERNER, Daniel \& Coleman, James. (1968), "Modernization", in International Encyclopaedia of the Social Sciences, Nova York, Macmillan.

LERNER, Daniel \& Schramm, W. (eds.). (1967), Comunication and change in developing countries. Honolulu, East-West Center Press.

LEVINE, Donald N. (1997), Visões da tradição sociológica. Rio de Janeiro, Zahar.

MARTIN-BARBERO, Jesus. (1998), De los ,édios a las mediaciones. Bogotá, Convenio Andrés Bejo.

MAUSS, Marcel. (1968), "Une catégorie de l'esprit humain: la notion de personne, celle de moi", in $\longrightarrow$ Sociologie et anthropologie, Paris, PUF.

MORISHIMA, Michio. (1987), Capitalisme et confucianisme. Paris, Flammarion.

MORRIS, Collin. (1972), The discovery of the individual: 1050-1200. Londres, S. P. C. K. for the Church Historical Society.
NISBET, Robert. (1967), The sociological tradition. Londres, Heinemann.

ORTIZ, Renato. (1985), "Memória coletiva e sincretismo científico:as teorias raciais do século XIX", in Cultura brasileira e identidade nacional, São Paulo, Brasiliense. (2000), O próximo e o distante: Japão e modernidade-mundo. São Paulo, Brasiliense.

POLLAK, Michael. (1986), "Max Weber en France: l'itinéraire d'une oeuvre". Cahiers de l'Institut d'Histoire du Temps Present, 3.

POMERANZ, Kenneth. (2000), The great divergence: China, Europe and the making of the modern world economy. Princeton, Princeton University Press.

QUIJANO, Aníbal (org.). (1991), Jose Carlos Mariátegui: textos básicos. México, Fondo de Cultura Económica.

RASMUSSEN, Anne. (1996), "À la recherche d'une langue internationale de la science", in Roger Chartier e Pietro Corsi (eds.), Sciences et langues en Europe, Paris, EHESS.

RODINSON, Maxime. (1989), "Les études arabes et islamiques en Europe" in , $\mathrm{La}$ Fascination de l'Islam, Paris, La Découverte.

ROSS, Dorothy. (1991), The origin of American social science. Cambridge, Cambridge University Press.

ROSTOW, W. (1964), Etapas do desenvolvimento econômico. Rio de Janeiro, Zahar.

SAID, Edward. ([1978] 2001), Orientalismo: o oriente como invenção do ocidente. São Paulo, Cia. das Letras.

SALA-MOULINS, Louis. (2008), Les misères des lumières. Paris, Homnisphère.

SHILS, Edward. (1965), "The calling of sociology", in Talcott Parsons (ed.), Theories of society, Nova York, The Free Press.

STEINER, Philippe. (2008), "La tradition française de critique de l'économie politique". Revue d'Histoire des Sciences Humaines, 1 (18).

SZTOMPKA, Piotr. (2010), "One sociologye or many?”, in Sujata Patel (ed.), The ISA hadbook of diverse sociological traditions, Londres, Sage.

TYRIAKIAN, Edward. (1966), "A problem for the sociology of knowledge: the mutual unawareness of Émile Durkheim and Max Weber". Archives Européennes de Sociologie, 7 (2). 
. (2001), "Traditions in sociology", in International Encyclopaedia of the Social and Behavioral Sciences, Amsterdam, Elsevier.

VERON, Eliseo. (1972), "Idéologie et production des connaissances sociologiques", in Luciano Martins (ed.), Amérique Latine: crise et dépendance, Paris, Anthropos.

VIEIRA PINTO, Álvaro. (1959), Ideologia e desenvolvimento nacional, Rio de Janeiro, Instituto Superior de Estudos Brasileiros.

WAGNER, Peter. (2004), "Formes d'Etat et formes de savoir social: traditions nationales et pluralité d'interprétations de la modernité", in B. Zimmermann, Les sciences sociales à l'épreuve de l'action, Paris, Éditions de la Maison des Sciences de l'Homme.

WAGNER, P.; Wittrock, B. \& Whitley, R. (eds.). (1991), Discourses on society: the shapping of the social science disciplines. Dordrecht, Kluwer Academi.

WALLERSTEIN, Immanuel (org.). (1996), Para abrir as ciências sociais. São Paulo, Cortez.

. (2006), "Ao 'direito de intervenção' dos países ocidentais", in L'universalisme européen: de la colonisation au droit d'ingérence, Paris, Demopolis.

YAMAZAKI, Masakazu. (1994), Individualism and the Japanese, Tokyo, Japan Echo.

ZEA, Leopoldo. (1965), El pensamiento latinoamericano. México, Pomarca. 


\section{AS CIÊNCIAS SOCIAIS E A DIVERSIDADE DOS SOTAQUES}

\section{Renato Ortiz}

Palavras-chave: Modernidade; Teoria sociológica; Mundialização; Eurocentrismo.

Este artigo retoma um tema clássico nas ciências sociais latino-americanas: a relação entre o seu desenvolvimento interno (nacional) e as influências externas. Trata-se, no entanto, de uma retomada que insere a problemática do pensamento sociológico no contexto da mundialização da cultura. Nesse sentido, para escapar à dicotomia entre pensamento nacional e pensamento cosmopolita, o autor propõe que as ciências sociais constituem uma língua com diferentes sotaques. Não existiria, portanto, um núcleo universal (identificado às teorias produzidas na Europa ou nos Estados Unidos) e um saber regional, identificado com os países ditos periféricos.

\section{THE SOCIAL SCIENCES AND THE DIVERSITY OF ACCENTS}

Renato Ortiz

Keywords: Modernity; Sociological theory; Globalization; Eurocentrism.

This article takes a classic theme in the social sciences in Latin America: the relationship between domestic development (national) and external influences. It is, however, a recommencement that introduces the problem of the sociological thinking in the context of the globalization of culture. In this sense, to escape the dichotomy between national thinking and cosmopolitan thinking, the author proposes that the social sciences are a language with different accents. There is not, therefore, a universal core (thus identified with theories produced in Europe or the United States) and a regional knowledge, identified with the so-called peripheral countries.
LES SCIENCES SOCIALES ET LA DIVERSITÉ DES ACCENTS

\section{Renato Ortiz}

Mots-clés: Modernité; Théorie sociologique; Mondialisation; Eurocentrisme.

Cet article revient sur un sujet classique des sciences sociales latino-américaines : le rapport entre son développement interne (national) et les influences externes. Il s'agit, néanmoins, d'un abordage qui insère la problématique de la pensée sociologique dans le contexte de la mondialisation de la culture. Ainsi, pour échapper à la dichotomie entre la pensée nationale et la pensée cosmopolite, l'auteur défend que les sciences sociales constituent un langage avec différents accents. Il n'existerait donc pas de noyau universel (identifié aux théories produites en Europe ou aux États-Unis) et un savoir régional, identifié avec les pays dits périphériques. 